\title{
Frequência de consumo de alimentos promotores do excesso de peso no primeiro ano de vida
}

\author{
Mariane Alves Silva, Poliana Cristina de Almeida Fonsêca, Sarah Aparecida Vieira, Carolina Abreu
} de Carvalho, Juliana Farias de Novaes, Sylvia do Carmo Castro Franceschini

\section{Resumo}

O excesso de peso é considerado atualmente um problema de saúde pública. De acordo com dados da Pesquisa de Orçamentos Familiares- POF (2008-2009) o número de crianças acima do peso dobrou nos últimos anos, passando de $15 \%$ para 34,8\%. O consumo alimentar está entre as causas do excesso de peso, passível de modificação. De acordo com Carrazzoni (2015), os alimentos que a criança tem contato na infância podem ser determinantes do seu estado nutricional. Avaliar a frequência de consumo de alimentos promotores do excesso de peso por crianças menores de um ano de idade. Estudo longitudinal com 116 crianças, acompanhadas no primeiro ano de vida na Policlínica Municipal de Viçosa. No $6^{\circ}$ e $9^{\circ}$ mês as crianças foram atendidas, sendo feitas orientações nutricionais às mães e entregue folders contendo informações sobre alimentação complementar e alimentos que deveriam ser evitados no primeiro ano de vida. Em outra consulta, no $12^{\circ}$ mês de vida, foi aplicado o Questionário de Frequência Alimentar (QFA), a fim de se verificar o consumo dos alimentos promotores do excesso de peso pelas crianças. A frequência de consumo foi categorizada em pelo menos uma vez na semana, quinzenalmente, raramente/nunca. Foram aferidos o peso e o comprimento, e calculado o IMC. Para avaliar associação do escore-z de IMC com a frequência de consumo alimentar foi realizado o teste Kruskal-Wallis. As análises estatísticas foram realizadas no software Stata 10.0, com nível de significância de 5\%. Todas as mães relataram o consumo de pelo menos um alimento promotor do excesso de peso pelas crianças. O maior consumo foi de Danoninho $(54,8 \%)$, pelo menos uma vez na semana. Destaca-se que, $72,8 \%$ das mães relataram que seus filhos nunca consumiram achocolatado e $53,1 \%$ das crianças nunca beberam refrigerante. Resultados satisfatórios foram observados para o consumo de biscoito recheado, chocolate e salgadinho, no qual $84,2 \%, 96,4 \%$ e $79,5 \%$ referiram raramente ou nunca terem consumido esses alimentos, respectivamente. Maiores valores de IMC se associaram positivamente com a ingestão de Danoninho em pelo menos uma vez na semana $(\mathrm{p}=0,018)$. Evidencia-se a importância de orientações nutricionais com apresentação de materiais educativos, uma vez que o consumo de alimentos promotores da obesidade foi inferior à outros estudos nacionais. Além disso, destaca-se que a maior parte das crianças não consumiam alimentos industrializados. Nesse contexto, o acesso das mães à informação é fundamental na tomada de decisões sobre os alimentos que devem ou não ser ofertados à criança.

Descritores: Consumo Alimentar; Alimentação Infantil; Sobrepeso. 